\title{
Determination of fluoride concentration in powdered milk in Iran 2010
}

\author{
Amir Hossein Mahvi ${ }^{1}$, Maryam Ghanbarian ${ }^{2}$, Marjan Ghanbarian ${ }^{3 *}$, Ahmad Khosravi ${ }^{3}$ \\ and Masoud Ghanbarian ${ }^{4}$ \\ ${ }^{1}$ School of Public Health and Center for Environmental Research, Tehran University of Medical Sciences, Tebran, Iran \\ ${ }^{2}$ Ministry of Health and Medical Education, Tehran, Iran \\ ${ }^{3}$ Shabroud University of Medical Sciences, Shabroud, Iran \\ ${ }^{4}$ Shiraz University of Medical Sciences, Shiraz, Iran
}

(Submitted 28 February 2011 - Final revision received 7 June 2011 - Accepted 20 June 2011 - First published online 28 September 2011 )

\section{Abstract}

High concentrations of fluoride (F) in powdered milk (formula milk) can have adverse health effects on the body. The $\mathrm{F}$ concentration in powdered milk was analysed in Iran in 2010. A total of twelve commercial brands of highly consumed powdered milk were selected to analyse the F content through the standard F ion-selective electrode method. From each brand, three samples with different production dates were selected. The means and standard deviation for F concentration in all the samples was 1.73 (SD 0.3 ) $\mu \mathrm{g} \mathrm{F} / \mathrm{g}$. The minimum and maximum F content in powdered milk brands Humana2 and Humana3 was 1.32 (SD 0.1) and 2.36 (sD 0.3 ) $\mu \mathrm{g}$ F/g, respectively. The study revealed that there was no significant difference in $\mathrm{F}$ concentration in the samples that belonged to various dates. Humana3 had a high $\mathrm{F}$ concentration (with an average of 2.36 ( $\mathrm{sD} 0.3) \mu \mathrm{g} \mathrm{F} / \mathrm{g}$ ), which can be a risk factor for increased dental fluorosis, especially when being prepared using water with a high content of $\mathrm{F}$.

\section{Key words: Infants: Powdered milk: Fluoride: Water: Teeth}

During the production procedure, baby powdered milk is processed as slurry in a rotating cylinder before being dehydrated. The existing water in the slurry vapourises and fluoride $(\mathrm{F})$ remains in the milk. Therefore, the $\mathrm{F}$ concentration in the water used during the processing can have an effect on the total $\mathrm{F}$ concentration in baby powdered milk. $\mathrm{F}$ is an element that can be supplied from foods and drinks. Excessive intake of $\mathrm{F}$ is known to cause a wide range of adverse health effects such as damaging the bones and teeth ${ }^{(1-4)}$.

Several previous studies ${ }^{(1-3,5-9)}$ have determined the $\mathrm{F}$ content of water, tea, baby foods and milk. Since milk $F$ is absorbable ${ }^{(9)}$, measuring $\mathrm{F}$ concentration in children's nutrition and milk is essential during the years in which children are at risk for fluorosis. It has been found that to be on the safe side for the risk of fluorosis or dental caries in future, the estimated mean daily $\mathrm{F}$ intake should be at or below $0.05 \mathrm{mg} \mathrm{F} / \mathrm{kg}$ of body weight for nearly all time points through the first 48 months of life ${ }^{(10)}$. In another survey, it was found that the study group for fluorosis ( $97 \%$ of which was mild) had significantly greater cumulative $\mathrm{F}$ intake from powdered infant formulas and other beverages with added water than did those without fluorosis ${ }^{(11)}$.
The purpose of the present study was to quantify the amount of $\mathrm{F}$ in the highly consumed baby powdered milk in Iran in 2010.

\section{Subjects and methods}

A total of twelve commercial brands of highly consumed powdered milk that included Humana1, Humana2, Humana3, Multi1, Multi2, Bebelac1, Bebelac2, Nan1, Nan2, Sama gold, Sama progres and Biomil were randomly collected from drugstores that were selling the highly consumed baby powdered milk on three different dates. First, the number and types of existing, permitted baby powdered milk available in drugstores were identified.

Samples were analysed in the Central Nutrition Laboratory of Tehran. F content was determined using the standard $\mathrm{F}$ ion-selective electrode method. The precision of this method is in the range of 0.02-1900 parts per million with $95 \% \mathrm{CI}$. This type of electrode incorporates a special ion-sensitive membrane, which may be a glass, a crystalline inorganic material or an organic ion exchanger. The membrane interacts specifically with the ion of choice, in our case $\mathrm{F}$, allowing the electrical potential of the half cell to be controlled

*Corresponding author: M. Ghanbarian, email ghanbarian1981@yahoo.com 
Table 1. Total fluoride $(F)$ content of twelve brands of Iranian baby powder milk

(Ranges, mean values and standard deviations)

\begin{tabular}{llll}
\hline & \multicolumn{3}{c}{$F$ content $(\mu \mathrm{g} \mathrm{F} / \mathrm{g})$} \\
\cline { 2 - 4 } Milk brand name & Range & Mean & SD \\
\hline Humana1 & $1.39-2.19$ & 1.73 & 0.41 \\
Humana2 & $1.24-1.44$ & 1.32 & 0.1 \\
Humana3 & $2.11-2.7$ & 2.36 & 0.3 \\
Multi1 & $1.48-1.76$ & 1.62 & 0.14 \\
Multi2 & $1.79-1.93$ & 1.86 & 0.07 \\
Bebelac1 & $1.50-1.66$ & 1.58 & 0.08 \\
Bebelac2 & $1.64-1.72$ & 1.68 & 0.04 \\
Nan1 & $1.66-1.85$ & 1.76 & 0.09 \\
Nan2 & $1.04-1.86$ & 1.44 & 0.4 \\
Sama Gold & $1.64-1.83$ & 1.74 & 0.09 \\
Sama Progres & $2.12-2.24$ & 2.18 & 0.06 \\
Biomil & $1.63-1.89$ & 1.76 & 0.13 \\
\hline
\end{tabular}

predominantly by the $\mathrm{F}$ concentration. All statistical analyses were performed using the software SPSS (version 16; Chicago, IL, USA).

\section{Results}

The result of the analysis of the highly consumed formula milk is demonstrated in Table 1 . The mean for $\mathrm{F}$ concentration in all the samples was 1.73 (SD 0.3$) \mu \mathrm{g} \mathrm{F} / \mathrm{g}$. The highest mean concentration was found in Humana3, with a mean $\mathrm{F}$ concentration of 2.36 (SD 0.3$) \mu \mathrm{g} \mathrm{F} / \mathrm{g}$. In other brands of formula milk, there was no significant difference in the $\mathrm{F}$ content. Humana2 with $1.32(\mathrm{SD} 0 \cdot 1) \mu \mathrm{g} \mathrm{F} / \mathrm{g}$ had the least concentration of $\mathrm{F}$ content among all the samples.

\section{Discussion}

Several studies ${ }^{(4,12-14)}$ have revealed that the amount of $\mathrm{F}$ received by the children cannot be measured only by examining F-added water, but should also be measured by examining other drinks and foods. Although quantification of the amount of $\mathrm{F}$ received by children is very demanding, it is obvious that there is a significant difference in the amount of $F$ from different foods and drinks.

The minimum and maximum $\mathrm{F}$ content was 1.32 (SD 0.1) and 2.36 (SD 0.3$) \mu \mathrm{g} \mathrm{F} / \mathrm{g}$ in Humana2 and Humana3, respectively. Humana3 had considerable amounts of $\mathrm{F}$ in comparison with other analysed powdered milk (2.36 (SD 0.3) $\mu \mathrm{g} \mathrm{F/g),}$ which can be a risk factor for developing fluorosis, especially when it is prepared with other sources of F such as water.

Therefore, the amount of $\mathrm{F}$ should be mentioned on the tin label of the baby powdered milk. Moreover, it may be essential to increase the $\mathrm{Ca}$ concentration of these products to reduce $\mathrm{F}$ absorption in the stomach and the intestine ${ }^{(13)}$.

Another effect of the products with a higher content of $\mathrm{Ca}$ is the reduction of the body's capability to absorb F. It should be considered that powdered milk has to be mixed with water for consumption. When the powdered milk is prepared with water containing $\mathrm{F}$, the existing $\mathrm{F}$ in the water would be added to the $\mathrm{F}$ absorption rate analysis. Thus, $\mathrm{F}$ in the water should be considered during the analysis ${ }^{(13)}$.

The high levels of $\mathrm{F}$ in Humana 3 may be the consequence of water consumed in the factory during the production procedure.

During the production procedure, baby powdered milk is processed as a slurry in a rotating cylinder before being dehydrated. The existing water of the slurry vapourises and $\mathrm{F}$ remains in the $\mathrm{milk}^{(13)}$. Therefore, the $\mathrm{F}$ concentration in the water used during processing can have an effect on the total $\mathrm{F}$ concentration in the baby powdered milk.

Fomon \& Ekstrand ${ }^{(12)}$ reported that $\mathrm{F}$ concentration in infant food that was produced with non-fluoridated water and F-added water was in the range of 0.09-0.2 and 4-6 parts per million, respectively. The present study revealed that $\mathrm{F}$ concentration in the analysed products belonging to three different production dates was not significantly different. Measurement of $\mathrm{F}$ concentration on various production dates was to prevent any inconsistency that usually occurs during the production process because of unwanted changes in water content. Silva Cardoso et al. ${ }^{(13)}$ reported that in the same region $\mathrm{F}$ concentration on various production dates was similar.

Another important factor for the development of fluorosis in children is the critical years during which they receive nutrition with $\mathrm{F}$ content. Evans \& Darvell ${ }^{(14)}$ proposed that the central incisor is exposed to a high risk of fluorosis development resulting from consuming nutrition with $\mathrm{F}$ content. This risk should be taken into consideration for male infants from 5 to 24 months old and for female infants from 21 to 35 months old. The critical period for incisors is after 12 months in which $\mathrm{F}$ absorption from nutrition produced by factories increases ${ }^{(4,14)}$. The labels on the baby powdered milk and the products of factories catering to children's nutrition should contain information on $\mathrm{F}$ concentration in addition to other nutritional facts.

\section{Acknowledgements}

The authors gratefully acknowledge the financial support of the Iranian government, which made the study possible. There are no conflicts of interest for any of the authors of the present study. M. G. collected the data and wrote the manuscript; A. H. M. designed the study; A. K. analysed the data; Maryam Ghanbarian and Masoud Ghanbarian collected the data and contributed to the manuscript.

\section{References}

1. Dobaradaran S, Mahvi AH \& Dehdashti S (2008) Fluoride content of bottled drinking water available in Iran. Fluoride 41, 93-94.

2. Dobaradaran S, Mahvi AH, Dehdashti S, et al. (2008) Drinking water fluoride and child dental caries in Dashtestan, Iran. Fluoride 41, 220-226.

3. Mahvi AH, Zazoli MA, Younecian M, et al. (2006) Fluoride content of Iranian black tea and tea liquor. Fluoride 39, $266-268$. 
4. Fomon SJ, Ekstrand J \& Ziegler EE (2000) Fluoride intake and prevalence of dental fluorsis: trend in fluoride intake with special attention to infants. J Public Health Dent 60, 131-139.

5. Burgstahler AW (2006) Fluoridated bottled water (editorial). Fluoride 39, 252-254.

6. Adair SM \& Wei HY (1978) Supplemental fluoride recommendations for infants based on dietary fluoride intake. Caries Res 12, 76-82.

7. Buzalaf MAR, Granjeiro JM, Damante CA, et al. (2001) Fluoride content of infant baby powders prepared with deionized, bottled mineral and fluoridated drink water. $J$ Dent Child 68, 37-41.

8. Van Winkle S, Levy SM \& Kiritsy MC (1995) Water and baby powder fluoride concentrations: significance for infants fed baby powder. Pediatr Dent 17, 305-310.

9. Ericsson Y (1958) State of fluoride in milk and its absorption and retention when administration in milk. Investigations with radio-active fluorine. Acta Odont Scand 16, 51-72.
10. Warren JJ, Levy SM, Broffitt B, et al. (2010) Consideration on optimal fluoride intake using dental fluorosis and dental caries outcomes - a longitudinal study. Fluoride $\mathbf{4 3}$, $253-254$

11. Levy SM, Broffitt B, Marshall TA, et al. (2010) Associations between fluorosis of permanent incisors and fluoride intake from infant formula, other dietary sources and dentifrice during early childhood. Fluoride 43, 254-255.

12. Fomon SJ \& Ekstrand J (1999) Fluoride intake by infants. J Public Health Dent 59, 229-234.

13. Silva Cardoso VE, Olympio KPK \& Granjeiro JM (2003) Fluoride content of several breakfast cereals and snacks found in Brazil. J Appl Oral Sci 11, 306-310.

14. Evans WR \& Darvell BW (1995) Refining the estimate of the critical period for susceptibility to enamel fluorosis in human maxillary central incisors. J Publ Health Dent $\mathbf{5 5}$ $238-249$. 